\title{
Benzene exposure is associated with epigenetic changes (Review)
}

\author{
CONCETTINA FENGA $^{1^{*}}$, SILVIA GANGEMI ${ }^{*}$ and CHIARA COSTA ${ }^{2 *}$ \\ ${ }^{1}$ Department of Biomedical and Dental Sciences and Morphofunctional Imaging; \\ ${ }^{2}$ Department of Clinical and Experimental Medicine, Occupational Medicine Section, \\ University of Messina, I-98125 Messina, Italy
}

Received April 19, 2015; Accepted February 4, 2016

DOI: $10.3892 / \mathrm{mmr} .2016 .4955$

\begin{abstract}
Benzene is a volatile aromatic hydrocarbon solvent and is known as one of the predominant air pollutants in the environment. Chronic exposure to benzene is known to cause aplastic anemia and increased risk of acute myelogenous leukemia in humans. Although the mechanisms by which benzene causes toxicity remain to be fully elucidated, it is widely accepted that its metabolism is crucial to its toxicity, with involvement of one or more reactive metabolites. Novel approaches aimed at evaluating different mechanisms by which benzene can impact on human health by altering gene regulation have been developed. Among these novel approaches, epigenetics appears to be promising. The present review article summarizes the most important findings, reported from the literature, on epigenetic modifications correlated to benzene exposure. A computerized search in PubMed was performed in November 2014, using search terms, including 'benzene', 'epigenetic', 'histone modifications', 'DNA methylation' and 'microRNA'. Epidemiological and experimental studies have demonstrated the potential epigenetic effects of benzene exposure. Several of the epigenomic changes observed in response to environmental exposures may be mechanistically associated with susceptibility to diseases. However, further elucidation of the mechanisms by which benzene alters gene expression may improve prediction of the toxic potential of novel compounds introduced into the environment, and allow for more targeted and appropriate disease prevention strategies.
\end{abstract}

Correspondence to: Professor Concettina Fenga, Department of Biomedical and Dental Sciences and Morphofunctional Imaging, Occupational Medicine Section, University of Messina, Via Consolare Valeria 1, I-98125 Messina, Italy

E-mail: cfenga@unime.it

${ }^{*}$ Contributed equally

Abbreviations: AML, acute myelogenous leukemia; DNMT, DNA methyltransferase; VOCs, volatile organic compounds

Key words: benzene, epigenetic, microRNA, DNA methylation, histone modifications, cancer

\section{Contents}

1. Introduction

2. Methods

3. Epigenetic mechanisms

4. Conclusions

\section{Introduction}

Benzene is a volatile aromatic hydrocarbon solvent and an important industrial chemical, which is present in petroleum products and combustion effluents. Owing to its chemical properties, benzene is known as one of the most common air pollutants in the environment (1). In the past, benzene was used predominantly as a solvent, however, occupational exposure in industrialized countries occurs through the production and use of petroleum derivatives, in particular fuels, in various settings, including factories, refineries, rubber production plants, shoe manufacturing and printing factories (2-4). The general population is exposed to benzene through inhalation; exposure sources include motor vehicle emissions, gasoline evaporative loss at service stations and cigarette smoke $(5,6)$. In addition, the consumption of contaminated foods or water can present a secondary route of exposure (7). The exposure to benzene can produce various health effects; available reports have suggested that occupational exposure to high doses of benzene can induce hematotoxicity, aplastic anemia and leukemia (8-11). Several studies have examined the possibility that benzene causes leukemia at high concentrations; however, it has since been suggested that exposure to levels $<10 \mathrm{ppm}$ increases the risk of acute and chronic leukemia (11-14). Although the mechanisms by which benzene causes toxicity remain to be fully elucidated, it is generally accepted that its metabolism is critical in the toxicity, with involvement of one or more reactive metabolites $(15,16)$. The metabolism of benzene predominantly occurs in the liver, where the P4502E1 cytochrome catalyzes the introduction of a single oxygen atom forming benzene oxide. However, previous studies have suggested that it is also metabolized and covalently bound in situ in bone marrow (17-20). Although benzene metabolism remains to be fully elucidated, numerous in vitro and in vivo studies have indicated that the primary products are phenol, catechol and hydroquinone, the majority of which are excreted in urine as glucuronide and sulphate conjugates $(17,21)$. However, catechol and hydroquinone can also be partially transformed 
into reactive $\mathrm{o}-$ and $\mathrm{p}$-benzoquinone, respectively. Benzene is also converted to a ring-opened oxidation product, $\mathrm{t}, \mathrm{t}$-muconic acid, via the precursor, t,t-muconaldehyde. In addition, benzene oxide can be a substrate of glutathione-S-transferase, forming mercapturic acid. There is evidence that hydroquinone, phenol, catechol, benzoquinone and muconaldehyde are actually involved in benzene toxicity; whereas the glutathione conjugate of mercapturic acid, and the glucuronide and sulphate conjugates of hydroquinone, catechol, phenol and benzoquinone are the results of detoxifying processes (22-24). These benzene metabolites are different in chemical structure and reactivity, therefore, it is difficult to determine which may contribute the most to producing benzene toxicity or leukemia. t, t-muconaldehyde and 1,4-benzoquinone are the most potent in inhibiting erythropoiesis, followed by hydroquinone and catechol, co-administration of phenol with hydroquinone and catechol, and certain glutathione adducts of hydroquinone (17). Furthermore, benzene exposure can cause damage to the immunological, neurological, and reproductive systems (25-27).

Previous studies have assessed the different mechanisms by which benzene can alter gene expression and cause toxicity in humans. Among these, epigenetics appears to be a promising tool. Epigenetics is the investigation of mitotically and meiotically heritable changes in gene expression without alterations in the DNA sequence. Several environmental factors have been associated to aberrant changes in epigenetic pathways in experimental and epidemiological studies (28-30). As these epigenetic changes are small, potentially cumulative and may develop over time, it may be difficult to identify the cause-effect links among environmental factors, epigenetic changes and diseases, and the role of environmental exposure in epigenetic alterations remains to be fully elucidated $(28,31,32)$.

Certain epigenetic mechanisms, including DNA methylation, histone modifications and microRNA (miRNA) expression, can alter genome function under the effects of several factors, including chemical and environmental toxins, age, gender or lifestyle. Epigenetic modifications may mediate specific mechanisms of toxicity and responses to certain xenobiotics. In addition, these alterations may persist even following removal of the triggering factor $(33,34)$.

The present review article summarizes the most important findings, reported from the literature, on epigenetic modifications correlated to benzene exposure (Table I).

\section{Methods}

In the present review, a computerized search in PubMed was performed in November 2014, using search terms, including 'benzene', 'epigenetic', 'histone modifications', 'DNA methylation' and 'microRNA'. Studies published in English, Italian and Chinese were included. The studies were selected according to the following criteria: Original study or meta-analyses; studies providing information on the association between benzene exposure and epigenetic modifications. Studies, which included detailed occupational exposure assessment, rather than those based solely on job titles were prioritized for selection. There were no restrictions with regard to the place of origin or the ethnicity of the subjects. The only restriction was to studies published in English, which reported the risk associated with benzene per se; risk estimates for benzene grouped with similar chemicals, for example other aromatic hydrocarbons, were excluded.

\section{Epigenetic mechanisms}

In the present review, three classes of epigenetic modifications were described: DNA methylation, post-translational histone modifications and miRNA expression.

DNA methylation is the most widely investigated epigenetic marker, which consists of the catalytic addition of a methyl group to the fifth carbon position of a cytosine residue, is followed on the same strand by guanine, and is also known as a $\mathrm{CpG}$ dinucleotide. Although their presence in the genome is rare, $\mathrm{CpG}$ dinucleotides occur in concentrations known as $\mathrm{CpG}$-islands, which can be found in the promoter region of $\sim 50 \%$ of all human genes (29). In normal cells, the promoter $\mathrm{CpG}$-island regions are characteristically non-methylated (29,35). CpG hypermethylation at promoter regions causes loss of function, whereas global hypomethylation at repetitive sequences causes genomic instability. These two types of alteration can contribute to a disease phenotype (28).

The second class of epigenetic changes includes the post-translational modification of the $15 \mathrm{e} 30$ amino acid $\mathrm{N}$-terminal unstructured histone tails. These modifications, involving the methylation of lysine and arginine residues, acetylation of lysine residues, phosphorylation of serine and threonine residues, ADP-ribosylation and ubiquitylation, can alter chromatin condensation, and all these modifications alter DNA transcription $(28,36)$. The functional consequences of these modifications depend on the specific amino acid involved and on the specific covalently bound group; acetylation determines the loosening of chromatin and leads to replication and transcription, whereas methylated histones tighten DNA and restrict access to various enzymes (37).

miRNAs are short single-stranded RNAs of $20-24$ nucleotides in length, which are transcribed from DNA but not translated into proteins. miRNAs negatively modulate the expression of target genes at the post transcriptional level by binding to the 3' untranslated regions of target mRNAs. Each mature miRNA is partially complementary to multiple target mRNAs, and directs the RNA-induced silencing complex to identify the target mRNAs for inactivation (38). Since the miRNA activity was confirmed in experimental and epidemiological studies involving animals and humans, miRNAs have gained significant attention due to their important modulatory effect on biological functions, including cellular proliferation, apoptosis, differentiation, metabolism and development. miRNAs also can chromatin structure and are involved in the maintenance of genome stability $(39,40)$.

The direct interaction between miRNAs and epigenetic modifications is considered to be a complex system. The expression of miRNAs is tissue-specific, and is accurately regulated by epigenetic mechanisms, including DNA methylation and histone modifications. By contrast, miRNAs can also alter epigenetic mechanisms, control gene transcription and target post-transcriptional gene-silencing (41).

DNA methylation. Aberrant DNA methylation models include global hypomethylation, gene-specific hypermethylation and 
Table I. Epigenetic modifications induced by benzene and its metabolites.

\begin{tabular}{|c|c|c|c|}
\hline Substance & Epigenetic changes & Type & Reference \\
\hline \multirow[t]{4}{*}{ Benzene } & $\begin{array}{l}\text { LINE-1 and Alu DNA hypomethylation; } \\
\text { gene-specific hypermethylation of } \\
\text { CDKN2B; hypomethylation of MAGE1 }\end{array}$ & Human & 32 \\
\hline & $\begin{array}{l}\text { Altered methylation induced by benzene at } \\
\text { several CpG sites; hypomethylation of } \\
\text { RUNX3 (AML2) gene; hypermethylation } \\
\text { of MSH3 gene and Sema3C protein }\end{array}$ & Human & 34 \\
\hline & $\begin{array}{l}\text { Downregulation of the expression of } \mathrm{p} 15 \\
\text { and p16 modulated by DNA promoter } \\
\text { methylation }\end{array}$ & Human & 35 \\
\hline & $\begin{array}{l}\text { LINE-1 and Alu DNA hypomethylation; } \\
\text { Hypomethylation of STAT3 }\end{array}$ & $\begin{array}{c}\text { Human } \\
37\end{array}$ & 33 \\
\hline Hydroquinone and 1,4-benzoquinone & $\begin{array}{l}\text { Hypermethylation of IL12 gene; } \\
\text { hypomethylation of RUNX1T1 and } \\
\text { MAGE-1 genes; } \\
\text { Global DNA hypomethylation }\end{array}$ & In vitro & 34 \\
\hline Benzene & Histone modifications & Mouse & 38 \\
\hline \multirow[t]{5}{*}{ Benzene } & $\begin{array}{l}\text { Upregulation of miR-154*, miR-487a, } \\
\text { miR-493-3p and miR-668; }\end{array}$ & Human & 34 \\
\hline & $\begin{array}{l}\text { Detected expressions of miR- } 638 \text {, } \\
\text { let- } 7 f-5 p \text { and miR-223-3p; }\end{array}$ & Human & 39 \\
\hline & $\begin{array}{l}\text { Upregulation of miR-34a, miR-205, } \\
\text { miR-10b, let-7d, miR-185 and } \\
\text { miR-423-5p-2; downregulation of } \\
\text { miR-133a, miR-543, hsa-miR-130a, } \\
\text { miR-27b, miR-223, miR-142-5p } \\
\text { and miR-320b; }\end{array}$ & Human & 40 \\
\hline & $\begin{array}{l}69 \text { miRNAs significantly differentially } \\
\text { expressed in volatile organic } \\
\text { compound-exposed samples. vs. controls; }\end{array}$ & Mouse & 41 \\
\hline & $\begin{array}{l}\text { Association between maternal expression } \\
\text { of miR-223 and indoor concentrations of } \\
\text { benzene; high expression levels of miR-223 } \\
\text { associated with lower regulatory T cell } \\
\text { numbers in maternal and cord blood }\end{array}$ & Human & 42 \\
\hline
\end{tabular}

miR, microRNA; LINE1, long interspersed element 1; CDKNB1 cyclin-dependent kinase inhibitor 2B; MAGE1, melanoma-associated antigen 1; RUNX2, runt-related transcription factor 2; MSH3, MutS homolog 3; STAT3, signal transducer and activator of transcription 3 , RUNX1T1, runt-related transcription factor 1 translocated to 1 .

hypomethylation; these changes are frequently reported in AML and other cancer tissues (41). It has been demonstrated significant long interspersed element 1 leukocyte and Alu DNA hypomethylation, as well as gene-specific hypermethylation of cyclin-dependent kinase inhibitor 2B and hypomethylation of melanoma-associated antigen 1 , is found in workers exposed to low doses of benzene (42). These results indicate that low-level benzene exposure may produce altered DNA methylation, resembling the aberrant epigenetic patterns of malignant cells. It was also found that DNA methylation, measured in specimen repeats collected at intervals of 8 years, decreased more markedly in exposed subjects, compared with control subjects, and an association of DNA epigenetic modifications in subjects exposed to low doses of benzene was demonstrated (43). A preliminary study using DNA extracted from the peripheral blood mononuclear cells of six workers exposed to benzene and four control individuals showed gender-specific methylation patterns for numerous genes, and also found altered methylation induced by benzene at several CpG sites (44).

A previous study involving 11 patients with benzene poisoning demonstrated that the average methylation level of 
p16, but not of p15, was higher than that in the control group. This result suggested that benzene may negatively alter the expression of p15 and p16 through DNA methylation. Patients with benzene poisoning exhibiting p15 and p16 promoter DNA methylation are more likely to develop AML, myelodysplastic syndrome and lymphoma (45).

To improve comprehension of the carcinogenic capacity of benzene, previous studies have investigated whether exposure to benzene and its metabolites modify the global DNA methylation status in human normal hepatic L02 cells. The alterations induced by the variation of DNA methyl transferase (DNMT) activity were also examined in an HaeIII DNMT-mediated methylation assay in vitro. The results indicated that hydroquinone and 1,4-benzoquinone produced global DNA hypomethylation with a statistically significant difference, compared with the control $(\mathrm{P}<0.05)$. These data suggested that hydroquinone and 1,4-benzoquinone can disturb global DNA methylation, and that global DNA hypomethylation induced by 1,4-benzoquinone may act through the inhibiting effects of DNMT activity at $101 \mathrm{M}(\mathrm{P}<0.05)(46)$.

By combining DNA methylation and mRNA expression data, Yang et al characterized three hypermethylated genes showing concurrent downregulation and two hypomethylated genes showing increased expression. It was hypothesized that aberrant hypomethylated signal transducer and activator of transcription 3 may arise from chronic benzene poisoning (47).

Histone modifications. Modified proteins have been detected in the liver and bone marrow of mice following treatment with 155 and $800 \mu \mathrm{g} / \mathrm{kg}$ b.w. $\left[{ }^{14} \mathrm{C}\right]$ benzene. The findings confirmed the high reactivity of benzene metabolites and their extensive binding to proteins. Detailed investigation of the histones demonstrated that their attack by reactive benzene species is broad, resulting in multiple modified sites within a single histone, and that the degree of ${ }^{14} \mathrm{C}$ incorporation is independent of the specific histone (48).

miRNAs. A preliminary study analyzed the miRNA expression levels in seven exposure-control matched pairs, and identified the upregulation of four miRNAs (miR-154*, miR-487a, miR-493-3p and miR-668) in the benzene-exposed subjects. Upregulation in the expression of miR-154*, possibly due to methylation and acetylation in the $14 \mathrm{q} 32$ region, has been reported in patients with acute promyelocytic leukemia bearing the $t(22 ; 17)$ translocation (44).

In a previous study, differentially expressed miRNAs in the plasma of benzene-exposed workers were examined, and the potential roles of plasma miRNAs in the development of hematologic toxicity induced by benzene exposure were investigated. Three significant classes of differentially expressed miRNAs were found using cluster analysis. The expression levels of miR-638, let-7f-5p and miR-223-3p, determined using reverse transcription-quantitative polymerase chain reaction analysis, was consistent with the microarray data. Pathway analysis showed that the most enriched pathway was focal adhesion, with six potential functional targets, including son of sevenless homolog 2, vinculin, cyclin D2, collagen type IV $\alpha 6$, insulin-like growth factor 1 and mitogen-activated protein kinase 1 (49).
In chronic benzene poisoning, six upregulated miRNAs (miR-34a, miR-205, miR-10b, let-7d, miR-185 and miR-423-5p-2) and seven downregulated miRNAs (miR-133a, miR-543, hsa-miR-130a, miR-27b, miR-223, miR-142-5p and miR-320b) were observed, compared with healthy controls $(\mathrm{P} \leq 0.05)$. The aberrant miRNA expression levels may be a potential biomarker of chronic benzene poisoning (50).

A previous study investigated whether miRNA expression profiles in the lungs of mice are modified by volatile organic compounds (VOCs) on 44 male Kunming mice. The mice were placed four similar static chambers, comprising a control group and three groups exposed to different doses of a VOC mixture. The results of the study indicated that inhalation of VOCs altered the miRNA patterns that regulate gene expression, potentially leading to the initiation of cancer and inflammatory diseases (51). Herberth et al analyzed the expression levels of miR-155 and miR-223, together with regulatory $\mathrm{T}$ (Treg) cell numbers in maternal blood during pregnancy, and in cord blood. An association was found between the maternal expression of miR-223 and the indoor concentrations of benzene and toluene, and also demonstrated that maternal tobacco smoke exposure during pregnancy was correlated with the expression level of miRNA-223 in the blood, with an effect on Treg cell numbers in the cord blood and subsequent allergy risk (52).

\section{Conclusions}

In the present review, the potential effects of benzene on the epigenome were evaluated. Occupational or environmental exposure to this solvent can produce epigenomic changes, which are associated with an increased susceptibility to the development of diseases (36). Whereas several studies have examined DNA methylation, few have considered the effects of environmental pollutants on histone modifications and miRNAs. Further investigations are required in order to assess the mechanisms by which environmental chemicals can modulate the epigenetic cellular setting. It is important to improve current knowledge on the effects of benzene exposure and the epigenetic alterations associated with several diseases. Further elucidation of the mechanisms by which benzene alters gene expression is likely to improve comprehension of the toxic potential of novel environmental pollutants, and to identify more appropriate preventative measures.

\section{References}

1. Rappaport SM, Kim S, Thomas R, Johnson BA, Bois FY and Kupper LL: Low-dose metabolism of benzene in humans: Science and obfuscation. Carcinogenesis 34: 2-9, 2013.

2. Wiwanitkit V: Classification of risk occupation for benzene exposure by urine trans, trans-muconic acid level. Asian Pac J Cancer Prev 7: 149-150, 2006.

3. Williams PR, Robinson K and Paustenbach DJ: Benzene exposures associated with tasks performed on marine vessels (circa 1975 to 2000). J Occup Environ Hyg 2: 586-599, 2005.

4. Wang L, Zhou Y, Liang Y, Wong O, Armstrong T, Schnatter AR, Wu Q, Fang J, Ye X, Fu H and Irons RD: Benzene exposure in the shoemaking industry in China, a literature survey, 1978-2004. Regul Toxicol Pharmacol 46: 149-156, 2006.

5. Mitacek EJ, Brunnemann KD, Polednak AP, Limsila T, Bhothisuwan $\mathrm{K}$ and Hummel CF: Rising leukemia rates in Thailand: The possible role of benzene and related compounds in cigarette smoke. Oncol Rep 9: 1399-1403, 2002. 
6. Harley RA, Hooper DS, Kean AJ, Kirchstetter TW, Hesson JM, Balberan NT, Stevenson ED and Kendall GR: Effects of reformulated gasoline and motor vehicle fleet turnover on emissions and ambient concentrations of benzene. Environ Sci Technol 40: 5084-5088, 2006.

7. Wallace LA: Environmental exposure to benzene: An update. Environ Health Perspect 104 (Suppl 6): S1129-S1136, 1996.

8. Pyatt D: Benzene and hematopoietic malignancies. Clin Occup Environ Med 4: 529-555, 2004.

9. Smith MT, Jones RM and Smith AH: Benzene exposure and risk of non-Hodgkin lymphoma. Cancer Epidemiol Biomarkers Prev 16: 385-391, 2007.

10. Lagorio S, Ferrante D, Ranucci A, Negri S, Sacco P, Rondelli R, Cannizzaro S, Torregrossa MV, Cocco P, Forastiere F, et al: Exposure to benzene and childhood leukaemia: A pilot case-control study. BMJ Open 3: e002275, 2013.

11. Snyder R: Leukemia and benzene. Int J Environ Res Public Health 9: 2875-2893, 2012.

12. Glass DC, Gray CN, Jolley DJ, Gibbons C, Sim MR, Fritschi L, Adams GG, Bisby JA and Manuell R: Leukemia risk associated with low-level benzene exposure. Epidemiology 14: 569-577, 2003

13. Khalade A, Jaakkola MS, Pukkala E and Jaakkola JJ: Exposure to benzene at work and the risk of leukemia: A systematic review and meta-analysis. Environ Health 9: 31, 2010.

14. Smith MT: Advances in understanding benzene health effects and susceptibility. Annu Rev Public Health 31: 133-148, 2010

15. Hatzi VI, Terzoudi GI, Pantelias GE, Spiliopoulou C and Makropoulos V: The benzene metabolite hydroquinone enhances G2-chromosomal radiosensitivity by inducing a less-efficient G2-M-checkpoint in irradiated lymphocytes. Int J Oncol 31: 145-152, 2007.

16. Melikian AA, Chen KM, Li H, Sodum R, Fiala E and El-Bayoumy K: The role of nitric oxide on DNA damage induced by benzene metabolites. Oncol Rep 19: 1331-1337, 2008.

17. Snyder R and Hedli CC: An overview of benzene metabolism Environ Health Perspect 104 (Suppl 6): S1165-S1171, 1996.

18. Irons RD, Dent JG, Baker TS and Rickert DE: Benzene is metabolized and covalently bound in bone marrow in situ. Chem Biol Interact 30: 241-245, 1980.

19. Subrahmanyam VV, Kolachana $P$ and Smith MT: Hydroxylation of phenol to hydroquinone catalyzed by a human myeloperoxidase-superoxide complex: possible implications in benzene-induced myelotoxicity. Free Radic Res Commun 15: 285-296, 1991

20. Subrahmanyam VV, Ross D, Eastmond DA and Smith MT: Potential role of free radicals in benzene-induced myelotoxicity and leukemia. Free Radic Biol Med 11: 495-515, 1991

21. Snyder R, Witz G and Goldstein BD: The toxicology of benzene. Environ Health Perspect 100: 293-306, 1993.

22. Costa C, Pupo C, Viscomi G, Catania S, Salemi M and Imperatore C: Modifications in the metabolic pathways of benzene in streptozotocin-induced diabetic rat. Arch Toxicol 73: 301-306, 1999.

23. McHale CM, Zhang L and Smith MT: Current understanding of the mechanism of benzene-induced leukemia in humans: implications for risk assessment. Carcinogenesis 33: 240-252, 2012.

24. Badham HJ and Winn LM: In utero and in vitro effects of benzene and its metabolites on erythroid differentiation and the role of reactive oxygen species. Toxicol Appl Pharmacol 244: 273-279, 2010.

25. Bogadi-Sare A, Zavalic M, Trosić I, Turk R, Kontosić I and Jelcić I: Study of some immunological parameters in workers occupationally exposed to benzene. Int Arch Occup Environ Health 73: 397-400, 2000

26. Bahadar H, Mostafalou S and Abdollahi M: Current understandings and perspectives on non-cancer health effects of benzene: A global concern. Toxicol Appl Pharmacol 276: 83-94, 2014

27. Reutman SR, LeMasters GK, Knecht EA, Shukla R, Lockey JE, Burroughs GE and Kesner JS: Evidence of reproductive endocrine effects in women with occupational fuel and solvent exposures. Environ Health Perspect 110: 805-811, 2002.

28. Stein RA: Epigenetics and environmental exposures. J Epidemiol Community Health 66: 8-13, 2012.

29. Christensen BC and Marsit CJ: Epigenomics in environmental health. Front Genet 2:84, 2011
30. Hou L, Zhang X, Wang D and Baccarelli A: Environmental chemical exposures and human epigenetics. Int J Epidemiol 41: 79-105, 2012.

31. Baccarelli A and Bollati V: Epigenetics and environmental chemicals. Curr Opin Pediatr 21: 243-251, 2009.

32. Kim M, Bae M, Na $\mathrm{H}$ and Yang $\mathrm{M}$ : Environmental toxicants-induced epigenetic alterations and their reversers. J Environ Sci Health C Environ Carcinog Ecotoxicol Rev 30: 323-367, 2012

33. Anway MD and Skinner MK: Epigenetic transgenerational actions of endocrine disruptors. Endocrinology 147 (Suppl 6): S43-S49, 2006.

34. Dolinoy DC and Jirtle RL: Environmental epigenomics in human health and disease. Environ Mol Mutagen 49: 4-8, 2008.

35. Chen QW, Zhu XY, Li YY and Meng ZQ: Epigenetic regulation and cancer (review). Oncol Rep 31: 523-532 2014.

36. Kanherkar RR, Bhatia-Dey N and Csoka AB: Epigenetics across the human lifespan. Front Cell Dev Biol 2: 49, 2014

37. Kouzarides T: Chromatin modifications and their function. Cell 128: 693-705, 2007.

38. Hou L, Wang D and Baccarelli A: Environmental chemicals and microRNAs. Mutat Res 714: 105-112, 2011.

39. Kitade Y and Akao Y: MicroRNAs and their therapeutic potential for human diseases: Micrornas, miR-143 and -145, function as anti-oncomirs and the application of chemically modified miR-143 as an anti-cancer drug. J Pharmacol Sci 114: 276-280, 2010

40. Zhang Y, Wang Z and Gemeinhart RA: Progress in microRNA delivery. J Control Release 172: 962-974, 2013.

41. Bollati V, Baccarelli A, Hou L, Bonzini M, Fustinoni S, Cavallo D, Byun HM, Jiang J, Marinelli B, Pesatori AC, et al: Changes in DNA methylation patterns in subjects exposed to low-dose benzene. Cancer Res 67: 876-880, 2007

42. Bollati V, Baccarelli A, Hou L, Bonzini M, Fustinoni S, Cavallo D, Byun HM, Jiang J, Marinelli B, Pesatori AC, et al: Changes in DNA methylation patterns in subjects exposed to low-dose benzene. Cancer Res 67: 876-880, 2007.

43. Fustinoni S, Bollati V and Bertazzi PA: Epigenic modifications associated with low benzene exposure. G Ital Med Lav Ergon 35: 263-267, 2013 (In Italian).

44. Zhang L, McHale CM, Rothman N, Li G, Ji Z, Vermeulen R, Hubbard AE, Ren X, Shen M, Rappaport SM, et al: Systems biology of human benzene exposure. Chem Biol Interact 184: 86-93, 2010.

45. Xing C, Wang QF, Li B, Tian H, Ni Y, Yin S and Li G: Methylation and expression analysis of tumor suppressor genes p15 and p16 in benzene poisoning. Chem Biol Interact 184: 306-309, 2010.

46. Hu J, Ma H, Zhang W, Yu Z, Sheng G and Fu J: Effects of benzene and its metabolites on global DNA methylation in human normal hepatic L02 cells. Environ Toxicol 29: 108-116, 2014.

47. Yang J, Bai W, Niu P, Tian L and Gao A: Aberrant hypomethylated STAT3 was identified as a biomarker of chronic benzene poisoning through integrating DNA methylation and mRNA expression data. Exp Mol Pathol 96: 346-353, 2014.

48. Williams KE, Carver TA, Miranda JJ, Kautiainen A, Vogel JS, Dingley K, Baldwin MA, Turteltaub KW and Burlingame AL: Attomole detection of in vivo protein targets of benzene in mice: Evidence for a highly reactive metabolite. Mol Cell Proteomics 1: 885-895, 2002

49. Liu Y, Zhang H, Chen X, Cao J, Zhong L, Ding L, Liu J and Zhu B: Screening and analysis of plasma microRNA profile in benzene exposed workers. Zhonghua Lao Dong Wei Sheng Zhi Ye Bing ZaZhi 32: 511-515, 2014 (In Chinese)

50. Bai W, Chen Y, Yang J, Niu P, Tian L and Gao A: Aberrant miRNA profiles associated with chronic benzene poisoning. Exp Mol Pathol 96: 426-430, 2014.

51. Wang F, Li C, Liu W and Jin Y: Modulation of microRNA expression by volatile organic compounds in mouse lung. Environ Toxicol 29: 679-689, 2014

52. Herberth G, Bauer M, Gasch M, Hinz D, Röder S, Olek S, Kohajda T, Rolle-Kampczyk U, von Bergen M, Sack U, et al: Maternal and cord blood miR-223 expression associates with prenatal tobacco smoke exposure and low regulatory T-cell numbers. J Allergy Clin Immunol 133: 543-550, 2014 